\title{
Artigo
}

\section{0 conceito de inconsciente à luz do recurso a Joyce: 0 último ensino de Lacan}

\author{
Cláudia Henschel de Lima ${ }^{\text {** }}$ (1) \\ Ciro Franco de Oliveirab ${ }^{b}$ \\ a Universidade Federal Fluminense, Departamento de Psicologia, Volta Redonda, Brasil \\ ${ }^{b}$ Universidade Federal do Rio de Janeiro, Programa de Pós-Graduação em Psicologia, Rio de Janeiro, Brasil
}

\begin{abstract}
Resumo: $\mathrm{O}$ artigo parte da interrogação: em que sentido o recurso à escrita de James Joyce abala a axiomática do ensino de Lacan, centrada no estruturalismo linguístico? $\mathrm{O}$ artigo visa, então, localizar a relevância do recurso a Joyce na reformulação do conceito de inconsciente. Por meio do levantamento conceitual sobre a definição do conceito de inconsciente, no ensino de Lacan, foi possível problematizar a validade do recurso à linguística estrutural para definir o conceito de inconsciente, interrogando o deslocamento desse recurso teórico para a obra de Joyce. A hipótese do artigo é que a evidência clínica da fala imposta, em um paciente psiquiátrico, e na própria experiência de Joyce, impôs à Lacan o trabalho epistemológico de problematizar o estatuto do significante como representativo do sujeito do inconsciente e, a partir daí, elaborar o conceito de inconsciente em sua relação com a experiência de gozo, e não em relação ao significante.
\end{abstract}

Palavras-chave: inconsciente, Joyce, psicanálise, linguística, gozo.

O objetivo do artigo é localizar a relevância da obra do escritor irlandês James Joyce na reformulação do conceito freudiano de inconsciente, tal como fora elaborado por Jacques Lacan. Por meio do levantamento conceitual sobre a definição do conceito de inconsciente, no ensino de Lacan, foi possível problematizar a validade do recurso à linguística estrutural para a definição do conceito de inconsciente, interrogando o deslocamento desse recurso teórico para a obra de Joyce. A hipótese para a razão deste deslocamento da linguística para a literatura é que a evidência quanto à irrupção da voz como objeto autonomizado (fala imposta), em Gérard Primeau paciente psiquiátrico hospitalizado e entrevistado por Lacan (1976/2000) em sua prática de apresentação de doentes - e no próprio Joyce, colocara para a teoria lacaniana o problema do estatuto do significante como representativo do sujeito do inconsciente.

Na época da apresentação de Primeau, Lacan (1976/2000) ressaltara a especificidade do estatuto do significante no caso, ao observar a irrupção de frases divorciadas de qualquer significação conforme o seguinte exemplo: "Ele vai me matar o pássaro azul. É um sistema anárquico. É um assassinato político ... um 'assastinato' político, que é a contração das palavras 'assassinato' e 'assistência', que evoca a noção de assassinato" (Lacan, 1976/2000, p. 6). A fala imposta será, então, explicitada por Primeau a Lacan, ao explicar que as palavras emergem espontaneamente, como uma explosão. Retomando essa explicação de Primeau, nas primeiras páginas de $O$ seminário, livro 23: o sinthoma, Lacan (1975-1976/2007) formula uma interrogação que indica a relevância que esse

*Endereço para correspondência: claudialima@id.uff.br modo específico de funcionamento da linguagem colocara para a própria teoria lacaniana: "Como é que todos nós não sentimos que as falas das quais dependemos são, de algum modo, impostas?" (p. 92). E, logo a seguir, afirma que o significante se reduz a um objeto autonomizado, a uma "torção de voz" (p. 92).

A partir da especificidade do funcionamento do significante, evidenciada pelo caso de Gérard Primeau, Lacan (1975-1976/2007) retoma a relação específica que o escritor irlandês James Joyce mantinha com as palavras interrogando se a fala imposta, se a torção de voz não seria também reconhecível no escritor: "é difícil não ver que uma certa relação com a fala lhe é cada vez mais imposta, ... a ponto de ele acabar por dissolver a própria linguagem" (p. 93). De fato, a reflexão de Joyce sobre a voz de seu pai - e, a seguir, sobre todas as vozes que o cercam como sendo vozes de ressonância-oca, ou a aplicação do procedimento de quebra, de desmantelamento do significante, até quase uma dissolução, são verificadas já em Um retrato do artista quando jovem (1914/2006). Consideremos uma breve passagem onde encontramos um exemplo de como Joyce - na figura do protagonista Stephen Dedalus - estabelece essa denominação:

ele ouvira à sua volta as vozes constantes do pai e dos mestres, instando para que fosse acima de tudo um cavalheiro e instando para que fosse acima de tudo um bom católico. ... e era o alarido dessas vozes de ressonância-oca que o fazia se deter irresolutamente em busca de fantasmas. (Joyce, 1914/2006, p. 94)

O caso de Gérard Primeau e o estilo de escrita de Joyce colocaram para Lacan esse problema, convocando-o 
a repensar não só o caráter representacional do significante como também o próprio conceito de inconsciente na via desse funcionamento representacional do significante. De que forma, então, o ensino de Lacan se desloca do recurso à linguística à escrita de Joyce?

Ao longo do seminário El lugar y el lazo, JacquesAlain Miller (2000-2001/2013) propôs um esforço de formalização do ensino de Lacan em torno de princípios e axiomáticas. Nesse esforço de formalização, o autor organizara o ensino de Lacan em quatro momentos: um pré-momento, que corresponderia à ênfase no imaginário; um segundo momento, que corresponderia, efetivamente, ao primeiro ensino com ênfase na lógica do significante; um terceiro momento, correspondendo ao segundo ensino com ênfase na elaboração do objeto $a$; e um quarto momento - terceiro ou último ensino de Lacan com ênfase no campo do gozo.

Com base nessa formalização proposta, o prémomento foi definido pelo princípio teórico do imaginário a partir do qual conduziu uma leitura da constituição do eu. Sua axiomática era a antropologia durkheimiana da família, articulando essa axiomática para pesquisar a etiologia psíquica das psicoses. $\mathrm{O}$ resultado foi $\mathrm{o}$ desenvolvimento da hipótese de que a situação do complexo familiar - mais precisamente sua composição, o estatuto do pai na família - determina a formação dos sintomas de sofrimento psíquico, sejam eles neuróticos ou resultantes de catástrofes estruturais como ocorre nas psicoses. Tal hipótese pode ser encontrada nos seguintes textos de Lacan"Formulações sobre a causalidade psíquica" (1946/1998), "O estádio do espelho como formador da função do eu” (1949/1998), Introdução teórica às funções da psicanálise em criminologia (1950/1998), O seminário, livro 1: os escritos técnicos de Freud (1953-1954/1983).

O primeiro ensino fora definido por dois princípios teóricos, a partir da axiomática da lógica do significante: (1) o inconsciente é estruturado como uma linguagem; (2) o significante é o que representa um sujeito para outro significante.

Tais princípios fundamentam o ensino de Lacan e estão na base dos seguintes textos de sua autoria: "Função e campo da fala e da linguagem em psicanálise" (1953/1998), O seminário, livro 2: o Eu na teoria de Freud e na técnica da psicanálise (1954-1955/1995), "De uma questão preliminar a todo tratamento possível da psicose" (1955-1956/1998), "O seminário sobre "A carta roubada"” (1956/1998), "A instância da letra no inconsciente ou a razão desde Freud" (1957/1998g), "A ciência e a verdade" (1965-1966/1998).

A leitura dessas referências, situadas no quadro desse primeiro ensino de Lacan, que compõem o projeto de retorno a Freud confronta o leitor com coordenadas importantes que resguardam a especificidade desse projeto. Recorrendo, então, à linguística estrutural de Ferdinand de Saussure e à antropologia de Claude Lévi-Strauss, tratava-se de redefinir o conceito de inconsciente a partir da noção de estrutura, conferindo a ele o estatuto preciso de uma matriz lógico-simbólica. Nessa perspectiva do primeiro ensino, as formações do inconsciente (sonho, ato falho, sintoma) - e considerando para fins deste artigo, especificamente, o sintoma - obedeceriam à estrutura lógico-simbólica:

é a essa ordem, e a nenhuma outra, que pertence o fenômeno do inconsciente, descoberta sobre a qual Freud fundou a psicanálise. Pois onde situar, por gentileza, as determinações do inconsciente senão nos quadros nominais em que se baseiam desde sempre, no ser falante que somos, a aliança e o parentesco, nas leis da fala em que as linhagens fundamentam seu direito, no universo de discurso em que elas misturam suas tradições? (Lacan, 1953/2003, pp. 143-144)

O recurso à noção de estrutura, para a definição do conceito de inconsciente, utilizada por Lacan durante o primeiro ensino impôs, então, sua redução à lei do significante.

O segundo ensino é definido pela elaboração da teoria do objeto $a$, tendo como referência principal O seminário, livro 11: os quatro conceitos fundamentais (1964/1985). A elaboração do objeto $a$ constituirá o corte epistemológico que fundará uma perspectiva distinta com relação à noção de estrutura e sua incidência na definição do conceito de inconsciente, que eram centrais em seu primeiro ensino. É, então, a partir do objeto $a$ e, consequentemente, da tomada de distância em relação à antropologia de Claude Lévi-Strauss que testemunharemos a aproximação entre o conceito de inconsciente e outro conceito freudiano fundamental: o conceito de pulsão. Sobre esse ponto em específico, Jacques-Alain Miller, em vários momentos de sua leitura epistemológica do ensino de Lacan (Miller, 1998-1990/2004, 1995-1996/2005, 2006-2007/2009, 2000-2001/2013, 2007-2008/2015), tem localizado, na elaboração conceitual do objeto $a$, a emergência de uma nova axiomática: a axiomática freudiana da pulsão. É no quadro dessa axiomática que Lacan (1964/1985) formalizará, por meio do objeto $a$, a presença de um resto que não é da mesma matéria linguística do significante. Essa formalização fica evidenciada em O seminário, livro 17: o avesso da psicanálise (19691970/1992), quando elabora a teoria dos discursos, redefinindo a lógica do significante e a dedução do sujeito a partir dela por meio de uma redução a três elementos, acrescentando um quarto elemento que, no primeiro ensino, ainda não aparecia: o objeto $a$. Dessa forma, a teoria dos discursos é composta por quatro elementos: o significante mestre (S1), o saber (S2), o sujeito (\$) e o objeto (a). Estes são articulados na fórmula do Discurso do Mestre (Lacan, 19691970/1992), conforme mostra a Figura 1: 


$$
\frac{\mathrm{S} 1}{\mathrm{~S}} \leftarrow \frac{\mathrm{S} 2}{a}
$$

Figura 1. Fórmula do Discurso do Mestre

Fonte: Lacan (1969-1970/1992, p. 75).

$\mathrm{Na}$ fórmula, identificamos a dedução do sujeito do inconsciente a partir do significante. Mas identificamos, também, um elemento posicionado na fórmula como produto do significante, mas que não se apresenta como ser de linguagem: o objeto $a$. A notação do objeto $a$ indica a presença de uma matéria bruta, já definida por Freud (1905/2016, 1920/2010) por meio do conceito de pulsão, para além da estrutura lógica do significante. De fato, na fórmula do Discurso do Mestre, o objeto $a$ ocupa, simultaneamente, o lugar de produto e ponto de resistência à ordem simbólica.

Até o momento temos que, no primeiro ensino, a linguagem é um dado fundamental: existe a linguagem, as regras de funcionamento da linguagem nos laços de parentesco. No segundo ensino, emerge a consideração de um resto que não é assimilado pela linguagem. Essa axiomática da pulsão é aprofundada no terceiro ensino e aparece de forma mais expressa no conteúdo de O seminário, livro 20: mais, ainda (1972-1973/1985). Aqui, testemunhamos o deslocamento do eixo de sua definição do conceito de inconsciente, do simbólico para o real, da estrutura para o gozo. Esse deslocamento lhe possibilitará redefinir o conceito de inconsciente a partir do limite da lógica do significante na definição do sujeito. O resultado é que se passa da problemática da lógica do significante para o Um. Em outras palavras, o significante não está reduzido à sua articulação com outro significante para a determinação do sujeito, conforme se verifica pela fórmula do Discurso do Mestre.

A tese central deste artigo é que o recurso à escrita de James Joyce em $O$ seminário, livro 23: o sinthoma (1975-1976/2007) será essencial para fundamentar essa nova perspectiva teórica sobre o conceito de inconsciente a partir da axiomática do gozo. A especificidade desse seminário, que tem a escrita de Joyce como eixo central, foi investigar o limite da lógica do significante com relação a sua potência de determinação do sujeito como sendo a carência constitutiva do sujeito pelo significante e a forma como um sujeito constrói uma suplência para essa carência.

Essa reformulação é extremamente importante por permitir alinhar o diálogo que a psicanálise, desde Freud, estabelecera com o domínio da arte (sejam as artes plásticas ou a literatura). Em especial, por permitir o diálogo da psicanálise com a arte desde o século XIX e presente nas obras de Mallarmé, Apollinaire, Ezra Pound, James Joyce e do poeta brasileiro Augusto de Campos (Rosa, 2009). É o recurso à especificidade dessa escritura presente na arte que permitirá a Lacan elaborar uma nova definição do conceito de inconsciente como memória de gozo.

No que se refere à importância precisa da escrita de James Joyce na redefinição do conceito de inconsciente,
Lacan (1975-1976/2007) considerara James Joyce como um gênio exemplar na construção de uma suplência diante do que, ao longo do artigo, será definido como a carência constitutiva do significante: desde a ressonância-oca da voz, passando pela quebra da linguagem, até a construção do Retrato. Tomando como referência a biografia de Joyce e o livro Um retrato do artista quando jovem (1914/2006), Lacan localizava aí o trabalho do escritor de construção de um nome, de um ego, por meio do retrato específico de um homem de letras, em um quadro de difícil relação com o pai.

$\mathrm{Na}$ lição de $O$ seminário, livro 23: o sinthoma (1975-1976/2007), dedicada à escrita do ego, Lacan utiliza expressões como quebra dos significantes e intrusão para se referir a essa função da escrita de Joyce. Sua hipótese é precisa: diante da carência do significante e dos efeitos de intrusão do gozo, oriundos dessa carência, a escrita funciona como suplência. Assim, conforme abordaremos ao longo deste artigo, por mais que, na história de vida de Joyce, este amasse o pai e fosse amado por ele, herdando vários traços positivos (é o caso da voz de tenor), o escritor descrevera seu pai também como um sujeito em bancarrota, um beberrão, um falido e um louvador de seu próprio passado que quase pusera, em função disso, a vida da família em risco (Joyce, 1914/2006). A escrita de Joyce evidenciaria, então, para Lacan (1975-1976/2007), o funcionamento do inconsciente não mais a partir da lógica do significante, mas a partir de um materialismo muito específico: ela seria um modo de solução para a carência constitutiva do sujeito pelo significante e dos efeitos de intrusão pelo gozo. Identificar como se articula a escrita de James Joyce a essa nova definição do conceito de inconsciente é a tarefa deste artigo.

\section{Do conceito de inconsciente estrutural ao conceito de sinthoma: por que Lacan recorre a James Joyce}

Conforme abordamos anteriormente, Lacan prosseguiu, ao longo de seu ensino, na direção de reformular o conceito de inconsciente no sentido de formalizá-lo a partir de quatro elementos em articulação. A fórmula do Discurso do Mestre oferece a exata dimensão dessa reformulação conceitual, ao incluir a dimensão do gozo, a partir da notação do objeto a na determinação do sujeito pela cadeia significante. Reconsiderando a Figura 1, observamos que a relação entre S1 e S2, localizada na parte superior da fórmula, indica a compreensão que Lacan (1969-1970/1992) tinha a respeito da linguagem: um significante (S1) se articula ao acaso com outro significante (S2). Essa articulação produz o sentido como efeito e está na gênese do sujeito, segundo a referência conceitual desta época. Dessa forma, observamos que a relação S1-S2 formaliza a passagem do acaso, dos significantes isolados (S1) ao sentido e ao sujeito. Assim, no quadro teórico desse momento do ensino de Lacan, o sujeito que fala de suas experiências infantis é, simultaneamente, falado pelos significantes transmitidos 
por alguém de sua família. Mas, em O seminário, livro 17: o avesso da psicanálise (Lacan, 1969-1970/1992), dedicado à elaboração da teoria dos discursos e à formalização do conceito de inconsciente a partir dessa teoria, identificamos, no objeto $a$, a especificidade do funcionamento do gozo, irredutível ao ser de linguagem. Observando a Figura 1, entendemos que Lacan (1969-1970/1992) formalizara o modo como os traços que o sujeito toma de empréstimo do Outro (S1) funcionam para representá-lo para os demais significantes da civilização (S2) ganhando valor de definição para ele. No entanto a notação do objeto $a$ indica a presença da experiência do gozo, que se refere ao sujeito para além de seu ser de linguagem. É essa notação que será aprofundada no terceiro momento do ensino de Lacan e possibilitará a redefinição do conceito de inconsciente como memória de gozo e uma nova compreensão do sintoma.

Entre o aprofundamento das consequências teóricas do objeto $a$ e a redefinição do conceito de inconsciente, situamos o recurso à escrita de James Joyce. De fato, já em O seminário, livro 20: mais, ainda, Lacan (1972-1973/1985) se refere à escrita de Joyce nos seguintes termos:

Joyce, não acho mesmo que não seja legível. . . . O que é que se passa em Joyce? O significante vem rechear o significado. É pelo fato de os significantes se embutirem, se comporem, se engavetarem ... que se produz algo que, como significado, pode parecer enigmático, mas que é mesmo o que há de mais próximo daquilo que nós analistas, graças ao discurso analítico, temos de ler - o lapso. (p. 51)

A citação é precisa: ela introduz uma função do significante já um tanto distinta de sua função, tal como se apresentava no quadro do primeiro ensino de Lacan: o significante é definido menos por sua função representativa do sujeito para outro significante do que por sua capacidade de se embutir, de se engavetar com outros significantes e, a partir daí, produzir significado. É no marco das formulações de Lacan (1972-1973/1985) que ressaltaremos a consolidação do seu terceiro ensino e a redefinição do conceito de inconsciente:

1. O seminário, livro 20: mais, ainda (19721973/1985): Lacan mantém a definição freudiana clássica do conceito de inconsciente: o inconsciente é o que se lê para além do que o sujeito diz. Essa definição preserva a ideia central de que o conceito de inconsciente define um saber que o sujeito detém, mas que não sabe e que se sustenta de um significante (S1). A partir dessa definição clássica, Lacan recorre à teoria dos conjuntos para formular a noção de enxame de significantes e deduz o conceito de inconsciente do enxame (essaim, homófono de "S1", em francês): o inconsciente é estruturado por um enxame de significantes heteróclitos que se engavetam, que se embutem. E sua notação pode ser escrita por meio do matema $\mathrm{S} 1(\mathrm{~S} 1(\mathrm{~S} 1(\mathrm{~S} 1 \ldots)))$.

2. "Conferência em Genebra sobre o sintoma" (1975/1998): aqui, Lacan dá continuidade à definição tomada de empréstimo da teoria dos conjuntos e acrescenta que todo significante (S1) pode servir de mensagem cifrada: um significante $(\mathrm{S} 1)$ condensa coisas absolutamente heteróclitas. A originalidade dessa outra definição do conceito de inconsciente em relação à que encontramos no quadro do segundo ensino de Lacan, orientado pela linguística estrutural, reside nesse estatuto material do significante (S1), que não está em remissão ao outro significante (S2), mas que condensa elementos heteróclitos em que o sujeito virá a se ancorar. $\mathrm{O}$ autor forja o termo motérialisme para sustentar que essa materialidade é a condição de possibilidade para a codificação: "É ... no motérialisme que reside a tomada do inconsciente - quero dizer que o que faz com que cada um não tenha encontrado outro modo de se sustentar não é senão o que, há pouco, chamei de sintoma" (Lacan, 1975/1998, p. 10).

3. "Introdução à edição alemã de um primeiro volume dos Escritos". (1973/2003): Lacan define o inconsciente por meio da metáfora do trabalhador ideal: "a descoberta de Freud de que o inconsciente trabalha sem pensar, nem calcular, nem tampouco julgar ... : um saber que se trata apenas de decifrar, já que ele consiste num ciframento" (Lacan, 1973/2003, p. 553). Mas para quem o inconsciente trabalha? A lógica do significante, que orientou o segundo momento do ensino de Lacan, não responde à pergunta. A indicação da resposta deve ser, então, buscada na axiomática do terceiro ensino: o inconsciente trabalha para a pulsão, para o gozo. É o gozo que está na causa, enganchando-se à materialidade do significante.

Essa breve ordenação verifica a nova axiomática que orienta o entendimento do conceito de inconsciente. Trata-se da presença do gozo. E o encontro com a especificidade da escrita de James Joyce assumiu o protagonismo desse deslocamento conceitual.

A ênfase deixa, então, de ser a noção de cadeia de significantes, que localiza o significante (S1) no campo mais vasto dos demais significantes da língua (S2) e a própria dedução do sujeito como produto da representação de S1 para S2. Ela passa a se localizar na noção de constelação, em que o S1 é entendido como ajuntamento de insígnias, de traços que funcionam sozinhos, independentes da cadeia de significantes. Tais significantes soltos operam como letra a partir da 
qual o sujeito se toma como Um, como substância. Essa nova definição, elaborada por Lacan (1971/2003, 19721973/1985), pode ser escrita por meio da fórmula exposta na Figura 2, construída para o artigo com base no escrito "Lituraterra" (Lacan, 1971/2003).

$$
\mathrm{S} 1(\mathrm{~S} 1(\mathrm{~S} 1(\mathrm{~S} 1(\mathrm{~S} 1 \rightarrow \mathrm{Sn})))
$$

Figura 2. Um esboço da fórmula da Constelação com base na leitura de Lituraterra

Fonte: Adaptado de "Lituraterra", de Lacan, 1971/2003.

Conforme a ênfase para a definição do conceito de inconsciente deixa de ser a linguística estrutural e sua concepção representacional do significante, Lacan torna evidente que o fundamento do sujeito e de sua relação com a própria linguagem é a pulsão, é o gozo, e não a significação.

A escrita do matema apresentado na Figura 2 evidencia com precisão essa mudança ao mostrar como a estrutura de remissão da cadeia significante (S1-S2), típica do primeiro ensino de Lacan, se modifica para os significantes tomados um a um ( $\mathrm{S} 1(\mathrm{~S} 1(\mathrm{~S} 1(\mathrm{~S} 1, \ldots))))$, para o enxame de significantes: fonemas, palavras, frases, pensamento. Tomando como ponto de apoio a obra de James Joyce, Lacan (1975-1976/2007) avançará nessa nova formulação a respeito do conceito de inconsciente e, consequentemente, da própria noção de sintoma. A título de organização do desenvolvimento conceitual trabalhado neste artigo, consideremos a leitura que Lacan (1975-1976/2007) faz das passagens do livro Um retrato do artista quando jovem (Joyce, 1914/2006). Essa leitura revela o processo de construção de um homem de letras, do artista, em resposta à carência estrutural do significante localizado, por sua vez, pelo próprio escritor irlandês, na desordem da casa paterna. Assim, Um retrato do artista quando jovem (Joyce, 1914/2006) evidencia como o engendramento do homem de letras, do artista, tem função de sintoma a partir de uma experiência com a linguagem muito particular e já mencionada no início deste artigo: a experiência da voz como ressonância-oca e que fazia o protagonista Stephen Dedalus "se deter irresolutamente em busca de fantasmas" (Joyce, 1914/2006, p. 94).

O valor de sintoma, assumido pelo engendramento do homem do artista, se explica não porque seja uma espécie de mensagem decifrável ou porque se liga a uma série de lembranças que sucumbiram à pressão do recalcamento, mas porque faz suplência à carência estrutural do significante localizada pela experiência da ressonância-oca. De fato, podemos depreender a carência estrutural do significante na forma alegórica usada por Joyce para descrever a irrupção da luz do sol sobre a vista de Stephen no quadro mais amplo da desordem de seu pai, para constatar a fuga de seus pensamentos e a função assumida pelos nomes que cita numa tentativa de assegurar seu ego (eu sou Stephen Dedalus):
A luz do sol, rompendo inesperadamente à sua vista, transformou o céu e as nuvens num mundo fantástico de sombrias massas com espaços, como lagos, de luz escura e rósea. Seu próprio cérebro estava doente e impotente. Ele mal podia interpretar as letras dos letreiros das lojas. Com a sua monstruosa maneira de vida parecia-lhe haver-se posto para além dos limites da realidade. Nada o movia ou lhe falava do mundo real a não ser quando um eco de gritos enfurecidos clamava dentro dele. Não podia responder a nenhum apelo do mundo ou dos homens, mudo e insensível à voz do verão, da alegria, da camaradagem, gasto e farto da voz paterna. Mal podia reconhecer os próprios pensamentos como seus, e repetia lentamente para si mesmo:

- Eu sou Stephen Dedalus. Estou andando ao lado do meu pai cujo nome é Simon Dedalus. Estamos em Cork, na Irlanda. Cork é uma cidade. Nosso quarto fica no hotel Victoria. Victoria e Stephen e Simon. Simon e Stephen e Victoria. Nomes. (Joyce, 1914/2006, p. 102-103)

Com essa leitura do conceito de inconsciente a partir do testemunho de Joyce, uma nova grafia é dada por Lacan (1975-1976/2007) ao sintoma, dando título ao $23^{\circ}$ seminário: sinthoma. Essa nova grafia aplicada ao conceito de sintoma é, na verdade, uma transliteração homofônica produzida por Lacan em O seminário, livro 23: o sinthoma (1975-1976/2007), tendo como base os termos saint-homme (santo homem) e sinthomemadaquin (sinthomasdiaquino), em alusão a Saint Thomas d'Aquin (São Thomas de Aquino) - filósofo escolástico, mencionado pelo próprio escritor irlandês no livro em questão. Retomando as definições de queda dos significantes e intrusão presentes neste seminário (Lacan, 1975-1976/2007), entendemos o estatuto de sinthoma que Lacan atribui à escrita de Joyce. Ela é um modo de solução para a carência constitutiva do sujeito pelo significante na forma da desordem da casa paterna de Stephen Dedalus, na forma de um pai em bancarrota, bem como dos efeitos de intrusão de gozo sofridos por Stephen, precisamente por permitir o engendramento do nome, do homem de letras. Sobre Simon Dedalus, pai do personagem Stephen Dedalus, James Joyce descreve testemunhalmente seu próprio pai, John Stanislaus Joyce como um sujeito falido e um louvador de seu próprio passado:

Um estudante de medicina, um tenor, um ator amador, um remador, um político gritador, um pequeno proprietário, um pequeno investidor, um beberrão, um bom homem, um contador de histórias, o secretário de alguém, um cobrador de impostos, um falido e atualmente um louvador de seu próprio passado. (Joyce, 1914/2006, pp. 253-254).

A partir da experiência radical com a linguagem, colhida por Lacan (1975-1976/2007) em sua leitura 
pontual de Um retrato do artista quando jovem (Joyce, 1914/2006), temos uma nova hipótese sobre a função do sintoma: compensar a carência do significante, articulando, enodando o funcionamento do inconsciente $\mathrm{e}$ a pulsão, o gozo. É isso que explica como Joyce delimita a carência do significante e localiza a construção do nome, do retrato de artista, como meta de vida.

\section{Quando o retrato tem valor de sinthoma}

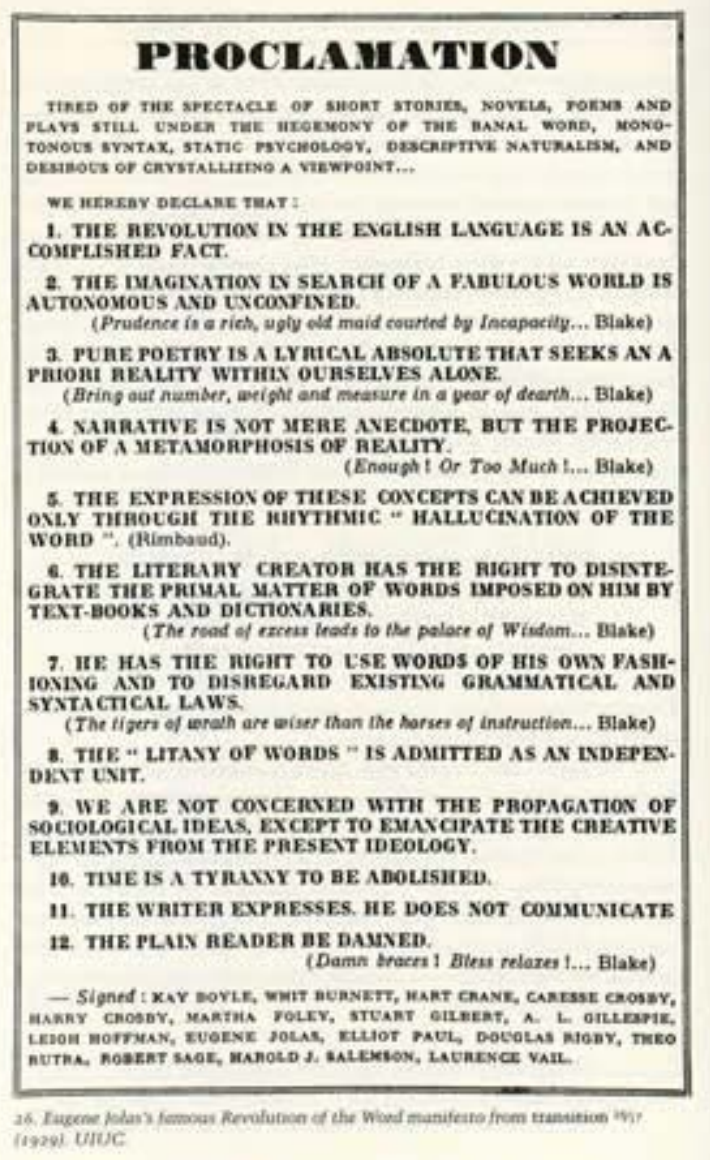

Figura 3. Manifesto de Transition - Proclamation

Fonte: Recuperado de https://bit.ly/3mU5fDD.

A revista de vanguarda Transition, de Eugene Jola (Figura 3), que difundira partes do livro Finnegans Wake (Joyce, 1939/2003), solicitara ao pintor espanhol César Abín que desenhasse um retrato do artista para ser publicado como homenagem por seu aniversário. César desenhara o retrato clássico de um homem de letras, sentado em frente a seu livro com uma caneta na mão e olhar visionário. Este pareceu muito solene a Joyce, que, durante duas semanas, orientara César Abín na elaboração de outro retrato, outra imagem pictórica de si mesmo na forma de ponto de interrogação, tal como verificamos na Figura 4. Observando a imagem, encontramos uma série de signos que compõem a materialidade do retrato que Joyce engendra de si mesmo, a partir do talento de César Abín (Santa Cecilia, 2014):
1. A forma em ponto de interrogação é uma alusão direta à descrição que Paul Léon, amigo de Joyce, fizera de sua figura. Joyce parecia um ponto de interrogação.

2. A presença do chapéu preto: no momento da confecção do retrato, Joyce estava de luto pela morte de seu pai.

3. Os remendos nas calças: Joyce recomendara que ficasse evidente sua condição de miserabilidade.

4. O globo terrestre que compõe o ponto de interrogação: ressalta a ilha da Irlanda, indicando a tarefa que toma para si, de (re)posionar a Irlanda definitivamente na cultura europeia.

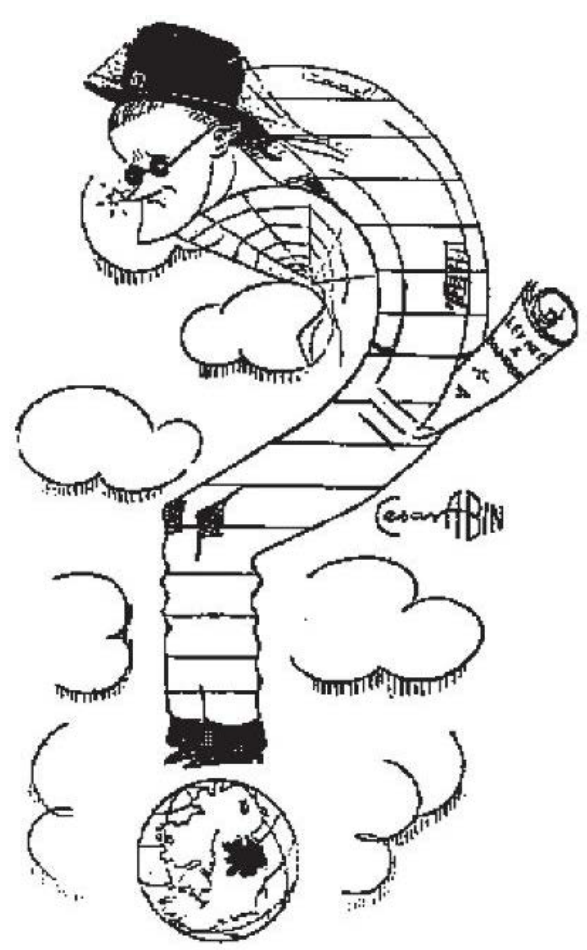

Figura 4. James Joyce (1932), por César Albín

Fonte: Recuperado de https://bit.ly/2WOzC3m.

A respeito da vida do autor, James Augustine Aloysius Joyce nasceu em 2 de fevereiro de 1882 no Condado de Dublin. Nascido no dia de Santa Brígida da Irlanda - a santa que, para os irlandeses, abençoa os poetas e é a encarnação da deusa celta Brigite, que inspira os bardos pela clarividência -, ele toma para si a tarefa de (re)posicionar a Irlanda definitivamente na cultura europeia, e sustenta que sua arte permitirá tal reposicionamento. Trata-se de uma tarefa complexa, pois a literatura irlandesa era plena de autores importantes, como: Jonathan Swift (1667-1745), Bram Stoker (18471912), Oscar Wilde (1854-1900), George Bernard Shaw (1856-1950), William Butler Yeats (1865-1939), Samuel Beckett (1906-1989) e Seamus Heaney (1939-2013).

Joyce era o mais velho de dez crianças sobreviventes e fora registrado incorretamente como James Augusta. 
Ao ser crismado, escolheu como seu nome o nome de um santo: Santo Aloísio. Assim, o nome de Joyce se transformara em James Agustine Aloysius Joyce. Seus pais eram John Stanislaus Joyce e Jane Mary Murray. A família de Joyce era católica e herdeira de grandes propriedades de terras que foram hipotecadas conforme se dava o nascimento dos filhos.

Seu pai fora coletor de impostos pela Dublin Corporation. Mas sua demissão, em 1893, marca o início da ruína financeira da família, testemunhada pelo próprio escritor em Um retrato do artista quando jovem (1914/2006) por meio do protagonista Stephen Dedalus. Referindo-se à biografia sobre John Stanislaus Joyce, escrita por Jackson e Costelo, Laia (2001) levantou recentemente a hipótese de que, nas profundezas da subjetividade de seu pai, Joyce teria usurpado o berço de seu irmão morto oito dias após o nascimento.

A morte do primogênito inscreve-se como uma falha na vida de John Stanislaus: ao não impedir a morte do filho mais velho, que perseveraria a série dos ancestrais encabeçada sempre pelo primogênito, ele havia falhado em perpetuar geracionalmente o que fizeram seu pai, seu avô e o bisavô paterno. Dessa forma, a morte interrompera a sequência convertendo John Stanislaus no último da linhagem paterna de sucessão de primogênitos homens. Embora John Stanislaus tenha pretendido transformar Joyce no mais digno de receber as histórias da família - ele lida com Joyce como se este fosse filho único, amando-o com uma intensidade que jamais fora encontrada na linhagem da relação de seus antepassados com os filhos únicos -, a ruptura na linhagem familiar e sua incidência trágica nas finanças da família seria irreversível. Na segunda gravidez de sua esposa, John Stanislaus hipotecou a primeira de uma série de onze propriedades herdadas e, após o nascimento de dez filhos, ele perdera tudo o que herdara, restando-lhe os filhos e uma quantia crescente de dívidas (Laia, 2001).

Esse é o marco da infância fragilizada de James Joyce: dominada, parasitariamente, pelo pai. As páginas de Um retrato do artista quando jovem (Joyce, 1914/2006) são ricas em verificar essa dominação parasitária. Podemos citar a passagem mencionada na abertura do artigo, em que o personagem de Stephen Dedalus reduz a voz constante de seu pai a uma ressonância-oca; o momento em que o autor evoca a história da vaquinha-mu, contada pelo senhor Simon Dedalus ao bebê-Stephen; a viagem à Cork que, adolescente, fizera com seu pai (onde este vivera) e onde ouve dele o seguinte testemunho para o qual reagiu com exaustão, tristeza e com uma estranheza que se abateu sobre a cadeia associativa de pensamento:

Não acredito em desempenhar o papel de pai severo. Não acredito que um filho deva temer seu pai. Não, eu o trato como seu avô me tratava quando eu era mocinho. Éramos mais como irmãos do que como pai e filho. Nunca esquecerei o primeiro dia em que ele me pegou fumando. Eu estava um dia em pé com alguns rapazolas como eu no final de South Terrace e com toda a certeza nos julgávamos o máximo porque tínhamos cachimbos enfiados nos cantos de nossas bocas. Subitamente, o meu velho passou. Ele não disse uma palavra ou sequer parou. Mas, no dia seguinte, um domingo, saímos juntos para um passeio a pé e quando estávamos voltando para casa ele tirou do bolso seu estojo de charutos e disse: "A propósito, Simon, eu não sabia que você fumava" ou alguma coisa do gênero. Naturalmente procurei enfrentar a situação da melhor maneira possível. "Se você quiser dar uma boa fumarada", disse ele, "experimente um destes charutos. Um capitão americano os deu de presente para mim ontem à noite em Queenstown. ... Ele ouviu o soluço descendo com barulho pela garganta do pai e abriu os olhos com um impulso nervoso. Seu próprio cérebro estava doente e impotente. Ele mal podia interpretar as letras dos letreiros das lojas.... Mal podia reconhecer os próprios pensamentos como seus, e repetia lentamente para si mesmo: - Eu sou Stephen Dedalus. Estou andando ao lado do meu pai cujo nome é Simon Dedalus. Estamos em Cork, na Irlanda. Cork é uma cidade. Nosso quarto fica no hotel Victoria. Victoria e Stephen e Simon. Simon e Stephen e Victoria. Nomes. (Joyce, 1914/2006, pp. 102-103).

O livro Um retrato do artista quando jovem foi publicado, inicialmente, na forma de capítulos em uma revista chamada The Egoist, nos anos de 1914 e 1915, e como livro completo em 1916. Está dividido em cinco capítulos com a seguinte estrutura: primeiro capitulo: testemunho da infância acentuadamente frágil do protagonista Stephen Dedalus; segundo capitulo: testemunho da entrada de Stephen na adolescência e de sua descoberta do amor; terceiro capitulo: testemunho da conversão do amor vivido por Stephen na adolescência em luxúria e a entrega do adolescente às prostitutas; quarto capítulo: testemunho do arrependimento do jovem Stephen, que padece de um conflito entre sua suposta vocação sacerdotal e o chamado artístico; quinto capitulo: todos os conflitos culminam na decisão de Stephen Dedalus pelo exílio, que o leva a se afastar da família, da pátria e da religião para se entregar à criação artística. É fundamental ressaltar que Dedalus é um nome grego que designa a personificação do espírito da arte.

A breve descrição da estrutura do livro evidencia que o testemunho de Joyce, por meio de Stephen Dedalus, ordena sua vida em torno de dois extremos: a fragilidade (tal como se apresenta no início do livro) e o exílio. E entre a fragilidade e o exílio, o autor posiciona a construção do artista, o engendramento do homem de letras, pelo espírito da arte e em forma daquele ponto de interrogação retratado por César Abín. Da mesma forma que Um retrato do artista quando jovem (Joyce 1914/2006) dá testemunho da dominância parasitária do pai sobre Stephen, ele também verifica a ordenação da vida do personagem entre a fragilidade e o exílio. 
No que se refere à fragilidade de Stephen, selecionamos três passagens que articulam esse caráter parasitário de imposição que a linguagem assume para o personagem, a partir da transmissão que é feita pelo sr. Simon Dedalus, e a fragilidade de Stephen. Conforme já mencionamos, essa fragilidade se insinua, então, logo nas primeiras páginas do livro, em que o protagonista dá o testemunho de uma história contada na infância por seu pai e cujo ritmo avança até se reduzir ao balbucio: "Era uma vez e uma vez muito boa mesmo uma vaquinha-mu que vinha andando pela estrada e a vaquinha-mu que vinha andando pela estrada encontrou um garotinho engrachadinho chamado bebê tico-taco (tuckoo, em inglês)" (Joyce, 1914/2006, p. 15). Esses sons e palavras - mu, engrachadinho, tico-taconão evidenciaram, para Lacan (1975-1976/2007), um trabalho por parte do escritor no sentido de simbolizar os balbucios da infância e de fixar o sujeito como representado pelo significante, conforme poderia sugerir uma perspectiva de leitura do significante baseada no segundo momento do ensino de Lacan. Mas evidenciara o estatuto parasitário, intrusivo, externo ao sujeito, dessas palavras e sons, desses S1, quando ganham independência da cadeia significante. Lacan (1975-1976/2007) localiza, nesses S1, a própria materialidade do inconsciente de Stephen Dedalus. A palavra tuckoo (tico-taco), por exemplo, usada pelo sr. Simon Dedalus para nomear Stephen como bebê tuckoo, reaparece ao longo de todo o livro. De fato, ela se repete em cuckoo, que significa tolo, maluco, idiota. E sugere o funcionamento do S1 em forma de constelação, de ajuntamento de insígnias, de traços que funcionam sozinhos, independentes da cadeia de significantes, conforme já descrevemos anteriormente e por meio do matema da constelação apresentado na Figura 2.

A fragilidade insinuada no início do livro pela história da vaquinha-mu que encontrara um garotinho engrachadinho chamado bebê tico-taco, irrompe em uma segunda passagem do livro, em que Joyce, relatando um diálogo de Stephen com os colegas de escola, aparentemente ordinário, mostra a posição subjetiva do personagem que é feito de tolo, de idiota:

Wells se aproximou de Stephen e disse: - Diga-nos, Dedalus, você beija sua mãe antes de ir para a cama? Stephen respondeu: - Beijo. Wells se virou para os outros companheiros e disse: - Ora, veja, aqui está um camarada que diz que beija sua mãe toda noite antes de ir para a cama. Os outros colegas pararam o jogo e se voltaram, rindo. Stephen corou, sob seus olhares e disse: - Eu não beijo. Wells disse: - Ora, veja, aqui está um camarada que diz que não beija sua mãe antes de ir para a cama. Todos riram novamente. Stephen tentou rir com eles. Sentiu todo o seu corpo ficar imediatamente confuso e quente. Qual era a resposta certa para a pergunta? (Joyce, 1914/2006, p. 22).
Dessa forma, o bebê tuckoo, que se impõe como cuckoo (tolo, maluco, idiota), ao mesmo tempo em que fixa a singularidade intrusiva do significante, já aponta para a especificidade da experiência trágica do personagem ("Sentiu todo o seu corpo ficar imediatamente confuso e quente. Qual era a resposta certa para a pergunta?") e da estabilização encontrada por uma escrita que comporá seu nome, que o eternizará como homem de letras.

Uma terceira passagem, que se refere à fragilidade do personagem, é o testemunho de ter sido espancado pelos colegas Nash, Boland e Heron, após uma discussão em que discorda de suas escolhas literárias e por questionar as acusações de heresia direcionadas a Lord Byron, um dos principais poetas do romantismo inglês. Lendo a passagem em que Stephen dá esse testemunho, destacamos a experiência de ver seu corpo quase tombar no chão como um fruto, que é despojado de sua casca madura e macia:

Finalmente depois de um furor de arremetidas ele conseguiu se livrar deles. Seus atormentadores partiram em direção a Jone's Road, rindo e zombando dele, enquanto ele, rasgado e afogueado e arquejante, tropeçava atrás deles semicego pelas lágrimas, cerrando loucamente os punhos e soluçando. . . . enquanto as cenas daquele episódio maligno passeavam ainda viva e rapidamente diante de sua mente, ele se perguntava por que agora não guardava rancor contra aqueles que o haviam atormentado. Não esquecera nem um pouquinho a covardia e a crueldade deles, mas a lembrança daquilo não lhe despertava nenhuma raiva. . . . Mesmo naquela noite enquanto tropeçava pela Jone's Road em direção a sua casa sentia que alguma força o estava despojando daquela raiva subitamente tecida tão facilmente quanto um fruto é despojado de sua casca madura e macia. (Joyce, 1914/2006, pp. 92-93)

Lacan (1975-1976/2007) destaca dois aspectos desse testemunho, centrais para a redefinição do conceito de inconsciente. $O$ primeiro se refere à ausência de afeto ligado à lembrança da surra; o segundo aspecto é o estatuto do corpo de Stephen no momento da surra: ele o experiencia como um objeto exterior à experiência subjetiva e que tomba como a casca de um fruto. Esse aspecto da exterioridade do corpo já havia se repetido em outro momento anterior do livro, quando Joyce relatara o espancamento de Stephen pelo prefeito de estudos: "Pensar nelas [em suas mãos] espancadas e inchadas de dor fazia com que por um momento sentisse pena delas como se não fossem parte dele, mas de outra pessoa de que ele sentisse pena" (Joyce, 1914/2006, p. 57).

Maleval (2014), em estudo recente sobre as psicoses ordinárias, dedica uma seção para pensar a função que a construção de um ego pode assumir em um quadro de fragilidade subjetiva extrema e na qual se verifica a ocorrência do abandono [laisser-tomber] do próprio corpo. $\mathrm{O}$ estudo ratifica a condição de fragilidade 
do próprio escritor James Joyce, subjacente à construção do protagonista Stephen Dedalus: "por negligência, ele deixou seu olho direito se calcificar, além de toda possibilidade de salvá-lo . . . ; ao mesmo tempo, ele quase não cuidou da úlcera que foi a origem de sua morte prematura" (Maleval, 2014, p. 121).

No que se refere ao exílio, encontramos uma referência importante ao final de Um retrato do artista quando jovem (1916/2006), onde Stephen decide pelo exílio em nome da criação artística, impondo seu afastamento da família, da pátria e da religião:

Abril, 16. Ir-me! Ir-me! O feitiço de braços e de vozes; os brancos braços das estradas; as suas promessas de íntimos abraços. E os negros braços dos navios imensos erguendo de encontro à lua sua narrativa de distantes nações. Estão erguidos para dizerem: "Estamos sós. - Vem". E as vozes dizem com eles:"Somos teus parentes". E o ar é denso com a companhia deles a me chamarem seu parente, prontos já para se irem, sacudindo as velas da sua exultante e terrível mocidade.

Abril, 26. Mamãe está colocando minhas roupas novas (de segunda mão) em ordem. E está rogando agora, diz ela, para que eu possa aprender na minha vida própria, e fora do lar e dos amigos, o que o coração é e o que ele sente. Amém. Assim seja. Sê bem-vinda, ó, vida! $\mathrm{Eu}$ vou ao encontro, pela milionésima vez, da realidade da experiência, a fim de moldar, na forja da minha alma, a consciência ainda não criada da minha raça. (Joyce, 1914/2006, p. 174)

A experiência do exílio autoimposto por Stephen Dedalus era uma resposta direta à desordem da casa paterna, aquela mesma desordem que John Stanislaus impôs à família ao hipotecar as propriedades herdadas restando-lhe um montante crescente de dívidas e o horizonte da falência. É importante localizar, conforme o testemunho de Stephen, a construção do artista entre o extremo da fragilidade subjetiva e o exílio. Lendo a passagem apresentada, percebemos exatamente esse ponto, no momento em que o protagonista afirma que vai à direção da realidade da experiência para moldar a consciência ainda não criada de sua raça, para construir, engendrar o artista, o homem de letras, pelo espírito da arte.

\section{Considerações finais}

"Como é que todos nós não sentimos que as falas das quais dependemos são, de algum modo, impostas?", pergunta Lacan (1975-1976/2007, p. 92) ao retomar o caso de Gérard Primeau em O seminário, livro 23: o sinthoma (1975-1976/2007).

A experiência com a fala imposta, inicialmente em Primeau e posteriormente no texto do escritor irlandês James Joyce, colocou para Lacan a exigência de reelaborar o conceito de inconsciente na direção de elucidar um modo específico de relação com a língua a partir da experiência do gozo. Conforme verificamos ao longo do artigo, a ênfase deixa de ser a lógica do significante pensada como representativa do sujeito e passa a se localizar na noção de constelação, em que o S1 é entendido como ajuntamento de insígnias que funcionam sozinhas, independentes da cadeia de significantes e de forma intrusiva, condensada com a experiência de gozo.

O encontro de Lacan (1975-1976/2007) com o longo processo de construção do nome, de engendramento do retrato de artista - e elevado à dignidade de horizonte de vida - possibilitou ao psicanalista defrontar-se, assim, com o limite do significante na determinação do sujeito e a possibilidade de criação por meio do sinthoma. É certo, então, que a axiomática do significante irá sofrer reformulação ao longo do ensino de Lacan na direção da axiomática do gozo. No entanto a dimensão de seriedade ressaltada por Lacan (1968-1969/2008) a respeito do recurso à estrutura se preserva no último ensino, na direção do conceito de gozo, ao que resiste à assimilação pelo significante. Por isso dedicamos centralmente o artigo não na lógica do significante, mas em Joyce, na escrita de Joyce, em uma obra específica do escritor e até mesmo na singularidade de um desenho pensado por ele mesmo. Essa centralidade na experiência singular é o legado de Lacan para as gerações futuras de psicanalistas e pesquisadores, sem abrir mão de uma teoria do inconsciente prise au sérieux.

\section{The concept of the unconscious in Joyce: Lacan's last teaching}

Abstract: This paper starts with a question: to what extent does James Joyce's writing style disrupts the axiomatic of Lacan's teaching, centered on linguistic structuralism? The text seeks therefore to pinpoint the relevance of resorting to Joyce when reformulating the concept of the unconscious. By means of a conceptual survey on the definition of the unconscious in Lacan's teaching, we problematized the validity of using structural linguistics to define such concept, inquiring about the displacement of this theoretical resource to Joyce's work. Our hypothesis posits that the clinical evidence of imposed speech, on a psychiatric patient and in Joyce's own experience, imposed on Lacan the epistemological work of problematizing the status of the signifier as representative of the subject of the unconscious, thus elaborating the concept of the unconscious in its relation to the experience of enjoyment rather than the signifier.

Keywords: inconscious, Joyce, psychoanalysis, linguistics, enjoyment. 


\section{Le concept de l'inconscient chez Joyce : le dernier enseignement de Lacan}

Résumé : Cet article commence par une question : dans quelle mesure le style d'écriture de James Joyce remet-il en cause l'axiomatique de l'enseignement de Lacan, centré sur le structuralisme linguistique ? Le texte cherche donc à relever la pertinence du recours à Joyce pour reformuler le concept d'inconscient. À travers l'étude conceptuelle sur la définition de l'inconscient dans l'enseignement de Lacan, nous avons problématisé la validité de l'utilisation de la linguistique structuraliste pour définir ce concept, en nous interrogeant sur le déplacement de cette ressource théorique vers l'œuvre de Joyce. Notre hypothèse postule que l'évidence clinique du discours imposé, sur un patient psychiatrique et dans la propre expérience de Joyce, imposaient à Lacan le travail épistémologique de problématiser le statut du signifiant comme représentant du sujet de l'inconscient, élaborant ainsi le concept d'inconscient dans son rapport à l'expérience de la jouissance plutôt qu'au signifiant.

Mots-clés : inconscient, Joyce, psychanalyse, linguistique, jouissance.

\section{El concepto de inconsciente bajo la luz del recurso a Joyce: la última enseñanza de Lacan}

Resumen: Este artículo parte del interrogante: ¿De qué manera el recurso a la escritura de James Joyce sacude la axiomática en la enseñanza de Lacan centrada en el estructuralismo lingüístico? El texto pretende encontrar la relevancia del recurso a Joyce en la reformulación del concepto de inconsciente. Desde el marco conceptual sobre la definición del concepto de inconsciente en la enseñanza de Lacan, fue posible problematizar la validez del recurso a la lingüística estructural en la definición de este concepto, interrogando su desplazamiento en la obra de Joyce. La hipótesis es que la evidencia clínica del habla impuesta en un paciente psiquiátrico y en la propia experiencia de Joyce impuso a Lacan el trabajo epistemológico de problematizar el estatuto del significante como representativo del sujeto del inconsciente para, desde ahí, elaborar el concepto de inconsciente en su relación con la experiencia de goce, pero no en relación al significante.

Palabras clave: inconsciente, Joyce, psicoanálisis, lingüística, goce.

\section{Referências}

Freud, S. (2016). Os Três Ensaios sobre a Sexualidade. In Obras completas (P. C. de Souza, Trad., Vol. 6 pp. 13-172). São Paulo, SP: Companhia das Letras. (Trabalho original publicado em 1905)

Freud, S. (2010). Além do princípio do prazer. In Obras completas (P. C. de Souza, Trad., Vol. 14, pp. 161-239). São Paulo, SP: Companhia das Letras. (Trabalho original publicado em 1920)

Joyce, J. (2006). Um retrato do artista quando jovem. Rio de Janeiro, RJ: Objetiva. (Trabalho original publicado em 1914)

Joyce, J. (2003). Finnegans Wake/Finnicius Revém (Vol. 5). São Paulo, SP: Ateliê Editorial. (Trabalho original publicado em 1939)

Lacan, J. (1983). O seminário, livro 1: os escritos técnicos de Freud, 1953-1954. Rio de Janeiro, RJ: Zahar.

Lacan, J. (1985). O seminário, livro 11: os quatro conceitos fundamentais, 1964. Rio de Janeiro, RJ: Zahar.

Lacan, J. (1985). O seminário, livro 20: mais, ainda, 1972-1973. Rio de Janeiro, RJ: Zahar.

Lacan, J. (1992). O seminário, livro 17: o avesso da psicanálise, 1969-1970 (A. Roitman, Trad.). Rio de Janeiro, RJ: Zahar.

Lacan, J. (1995). O seminário, livro 2: o Eu na teoria de Freud e na técnica da psicanálise, 1954-1955 (M. C. Laznik-Penot, Trad.). Rio de Janeiro: Jorge Zahar.
Lacan, J. (1998). Formulações sobre a causalidade psíquica. In Escritos (V. Ribeiro, Trad., pp. 152-194). Rio de Janeiro, RJ: Zahar. (Trabalho original publicado em1946)

Lacan, J. (1998). O estádio do espelho como formador da função do eu. In Escritos (V. Ribeiro, Trad., pp. 96-103). Rio de Janeiro, RJ: Zahar. (Trabalho original publicado em 1949)

Lacan,J.(1998). Introduçãoteóricaàsfunçõesdapsicanáliseem criminologia. In Escritos (V. Ribeiro, Trad.,pp. 127-151). Rio de Janeiro, RJ: Zahar. (Trabalho original publicado em 1950)

Lacan, J. (1998). Função e campo da fala e da linguagem em psicanálise. In Escritos (V. Ribeiro, Trad., pp. 238-324). Rio de Janeiro, RJ: Zahar. (Trabalho original publicado em1953)

Lacan, J. (1998). De uma questão preliminar a todo tratamento possível da psicose. In Escritos (V. Ribeiro, Trad., pp. 537-590). Rio de Janeiro, RJ: Zahar. (Trabalho original publicado em 1955-1956)

Lacan, J. (1998). O seminário sobre “A carta roubada”. In Escritos (V. Ribeiro, Trad., pp. 13-66). Rio de Janeiro, RJ: Zahar. (Trabalho original publicado em 1956)

Lacan, J. (1998). A instância da letra no inconsciente ou a razão desde Freud. In Escritos (V. Ribeiro, Trad., pp. 496-533). Rio de Janeiro, RJ: Zahar. (Trabalho original publicado em 1957) 
Lacan, J. (1998). A ciência e a verdade. In Escritos (V. Ribeiro, Trad., pp. 869-892). Rio de Janeiro, RJ: Zahar. (Trabalho original publicado em 1965-1966)

Lacan, J. (1998). Conferência em Genebra sobre o Sintoma. Opção Lacaniana, 23, 6-16. (Trabalho original publicado em 1975)

Lacan, J. (2000). Uma psicose lacaniana: entrevista conduzida por Jacques Lacan. Opção Lacaniana, 25, 5-16. (Trabalho original publicado em 1976)

Lacan, J. (2003). Discurso de Roma. In Outros escritos (V. Ribeiro, Trad., pp. 139-172). Rio de Janeiro, RJ: Zahar. (Trabalho original publicado em 1953)

Lacan, J. (2003). Lituraterra. In Outros escritos (V. Ribeiro, Trad., pp. 15-25). Rio de Janeiro, RJ: Zahar. (Trabalho original publicado em 1971)

Lacan, J. (2003). Introdução à edição alemã de um primeiro volume dos Escritos. In Outros escritos (V. Ribeiro, Trad., pp. 550-556). Rio de Janeiro, RJ: Zahar. (Trabalho original publicado em 1973)

Lacan, J. (2007). O seminário, livro 23: o sinthoma, $1975-$ 1976 (S. Laia, Trad.). Rio de Janeiro, RJ: Zahar.

Lacan, J. (2008). O seminário, livro 16: de um Outro ao outro, 1968-1969 (V. Ribeiro, Trad.). Rio de Janeiro, RJ: Zahar.

Laia, S. (2001). Os escritos fora de si: Joyce, Lacan e a loucura. Belo Horizonte, MG: Autêntica.

Maleval, J.-C. (2014) Elementos para uma apreensão clínica da psicose ordinária. Clínica \& Cultura, 3(1), 105-169.
Miller, J.-A. (2004). La experiencia de lo real en la cura psicanalitica. Buenos Aires: Paidós. (Trabalho original publicado em 1998-1999)

Miller, J.-A. (2005). El Otro que no existe y sus comités de ética. Buenos Aires: Paidós. (Trabalho original publicado em 1995-1996)

Miller, J.-A. (2009). Perspectivas do seminário 23 de Lacan: o sinthoma. Rio de Janeiro, RJ: Zahar. (Trabalho original publicado em 2006-2007)

Miller, J.-A. (2013). El lugar y el lazo. Buenos Aires: Paidós. (Trabalho original publicado em 2000-2001)

Miller, J.-A. (2015). Todo el mundo es loco. Buenos Aires: Paidós. (Trabalho original publicado em 2007-2008)

Rosa, M. (2009). Da cadeia significante à constelação de letras: os signos do gozo. Ágora: Estudos em Teoria Psicanalitica, 12(1), 53-73. doi: 10.1590/S151614982009000100004

Santa Cecilia, C. (2014). El amigo de Gómez de la Serna que retrató a James Joyce. Negritasycursivas: Libros e Historia Editorial. Recuperado de https:// bit.ly/3kHdXSX
Recebido: $24 / 10 / 2018$

Revisado: $17 / 03 / 2020$

Aprovado: 10/08/2021 